\title{
MICROSTRUCTURAL CONDITIONS CONTRIBUTING TO FATIGUE VARIABILITY IN P/M NICKEL-BASE SUPERALLOYS
}

\author{
W.J. Porter, $\mathrm{III}^{1}$, K. Li ${ }^{1}$, M.J. Caton, S. Jha ${ }^{2}$, B. B. Bartha ${ }^{2}$, and J.M. Larsen \\ AFRL/MLLMN \\ Materials \& Manufacturing Directorate \\ Air Force Research Laboratory \\ Wright-Patterson AFB, OH \\ ${ }^{1}$ The University of Dayton Research Institute \\ ${ }^{2}$ Universal Technology Corporation
}

Keywords: nickel, superalloy, IN100, René88DT, fatigue, variability, image correlation

\begin{abstract}
Variability in the fatigue behavior of two common nickel-base superalloys is discussed, with emphasis given to understanding the behavior of short fatigue cracks. René88DT and IN100 are the materials of interest and serve important roles in many turbine engine systems. Multiple specimens of each material were tested under low cycle fatigue (LCF) conditions at elevated temperature. Two IN100 specimens that exhibited significant difference in cycles to failure and three René88DT specimens having dissimilar short fatigue crack growth rates were interrogated to determine the reasons for these variations. This paper will discuss the microstructure adjacent to the initiation sites in these specimens and its role in affecting the observed disparate crack growth behavior. Additionally, an image correlation technique, used to evaluate the development of strain concentrations in a René88DT tensile specimen at room temperature, is described. The utility of image correlation for identifying microstructural 'hot spots' (i.e. initiation sites) in concert with LCF testing is considered.
\end{abstract}

\section{Introduction}

Life prediction models that integrate the inherent fatigue variability of materials used in gas turbine engines are of interest to the USAF. Past research indicates that much of the variability seen in fatigue behavior is related to material response in the presence of small $(<100 \mu \mathrm{m})$ fatigue cracks [1,2]. While extensive databases of long crack growth data exist for nickel-base superalloys, similar databases for small crack growth data are lacking, as is our general understanding of their behavior particularly under LCF conditions. Factors associated with differences in small crack behavior include local microstructural features including neighboring grain (mis)orientation, grain substructure ( $\gamma^{\prime}$ precipitates), twins, and anomalies such as the presence of inclusions and pores [3-7].

René88DT and IN100 are important alloys in the field of Ni-base powder metal superalloys in turbine engine applications. They are the focus of this paper due to their important role in US Air Force (USAF) propulsion systems. A current focus of USAF materials research pertains to the development of life prediction methodologies based on determining remnant component capability via prognostic approaches. The ultimate goal of this work is to arrive at a better understanding of those factors central to influencing fatigue variability to aid future USAF lifemanagement efforts.

\section{Experimental}

$\underline{\text { Material }}$

The alloys investigated in this study were René88DT and IN100. Both are powder metal processed materials that were solution treated above the gamma prime $\left(\gamma^{\prime}\right)$ solvus temperature (supersolvus). The sources of material for each alloy were large pancake forgings produced using standard industrial practices. The nominal composition and microstructure of each alloy are shown in Table I and Figure 1, respectively. The average grain size of the René88DT of approximately $30 \mu \mathrm{m}$ (Fig. 1a); the microstructure is highlighted by a large number of annealing twins and very fine $\gamma^{\prime}$ phase material that forms upon cooling with diameters on the order of $200 \mathrm{~nm}$ (Fig. 1b). Aging or tertiary $\gamma$, phase, although not apparent in Fig 1b, is also present and reported to be approximately $100 \AA$ in size [8].

The grain size of the IN100 is approximately $25 \mu \mathrm{m}$ (Fig 1c). A bi-modal distribution of $\gamma^{\prime}$ particles is formed upon cooling from annealing, with the cooling $\gamma^{\prime}$ having diameters of $1 \mu \mathrm{m}$ (Fig. 1d) and the aging $\gamma^{\prime}$ having diameters of $\sim 100 \mathrm{~nm}$. Twinning is apparent in the IN100, but not as prevalent as in the René88DT.

The tensile properties corresponding to the temperatures at which the fatigue testing was conducted for each alloy follow. At 593C, the René88DT has a $0.2 \%$ offset yield of $985 \mathrm{MPa}$ and an elastic modulus of $176 \mathrm{GPa}$ [3]. At 650C, the IN100 measured a $0.2 \%$ yield of $888 \mathrm{MPa}$, ultimate tensile stress of $1225 \mathrm{MPa}$, an elastic modulus of $175 \mathrm{GPa}$, and a strain at failure of $41 \%$.

\section{$\underline{\text { Testing Procedure }}$}

Cylindrical dog-bone specimens having a nominal gage diameter

Table 1. Nominal composition of René88DT and IN100 (Weight Percent)

\begin{tabular}{|ccccccccccccc|}
\hline & Co & $\mathrm{Cr}$ & $\mathrm{Mo}$ & $\mathrm{W}$ & $\mathrm{Al}$ & $\mathrm{Ti}$ & $\mathrm{V}$ & $\mathrm{N}$ & $\mathrm{B}$ & $\mathrm{C}$ & $\mathrm{Zr}$ & $\mathrm{Ni}$ \\
\hline R88DT & 13 & 16 & 4 & 4 & 2.1 & 3.7 & & 0.7 & 0.01 & 0.03 & 0.03 & bal \\
IN100 & 18.5 & 12.4 & 3.2 & & 5.5 & 4.7 & 0.8 & & & 0.07 & bal \\
\hline
\end{tabular}


of $6.35 \mathrm{~mm}$ were used in this study. The specimens were extracted such that the tensile axes were parallel to the circumference of each forging. All of the specimens were machined to a low stress grind (LSG) finish. The IN100 specimens were tested in the LSG surface condition. To further minimize the effects of surface residual stresses due to machining, the gage sections of the René88DT specimens were electropolished using a procedure described in [3].

The René88DT specimens were tested under load control at $1250 \mathrm{MPa}, 593^{\circ} \mathrm{C}$, a frequency of $0.33 \mathrm{~Hz}$, and a stress ratio of 0.05. All IN100 testing was also done under load control at $1100 \mathrm{MPa}, 650^{\circ} \mathrm{C}$, a frequency of $0.33 \mathrm{~Hz}$ and a stress ratio of 0.05 . The stress levels chosen for each group of specimens are representative of low cycle fatigue (LCF) conditions.

Replicate testing of René88DT specimens at $1250 \mathrm{MPa}$ using the conditions previously described in concert with the electropolished gage sections resulted in a predominance of surface-nucleated cracking. The surface-nucleated cracking

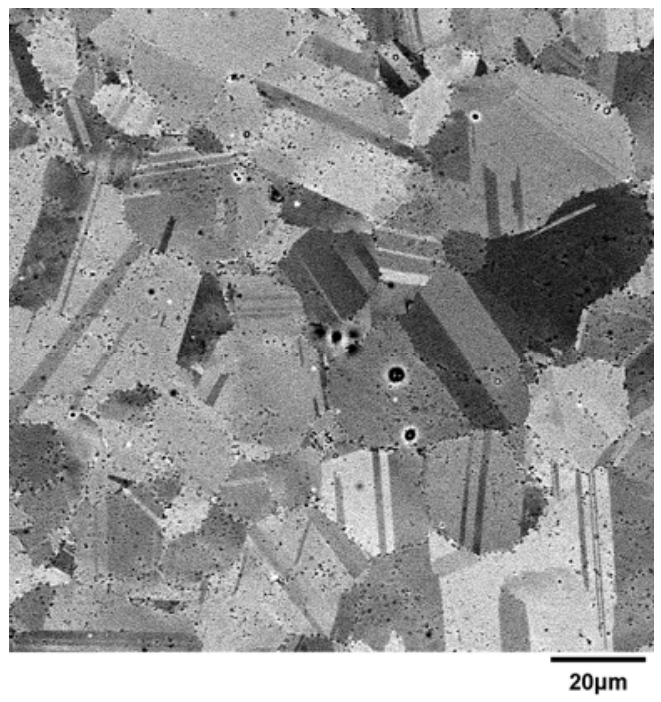

a)

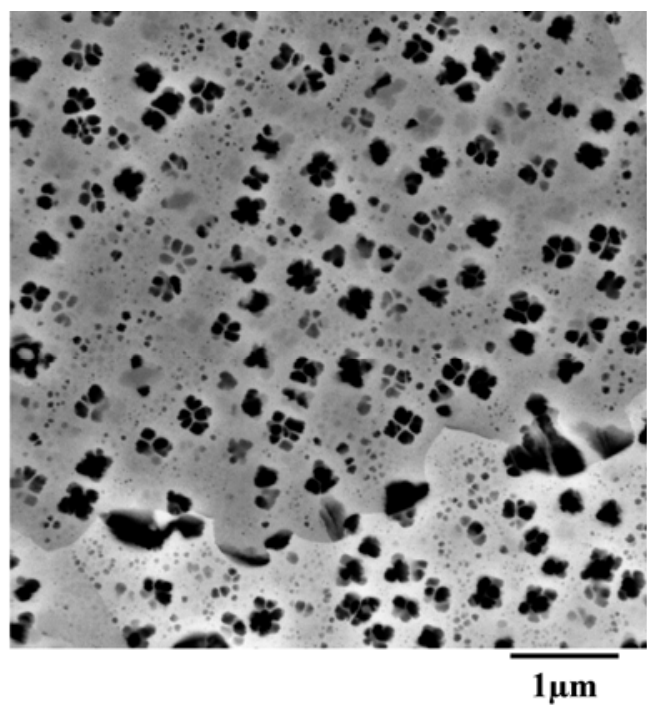

b) served as a convenient platform for investigating variable short crack growth rates using acetate replication techniques. Surface replicas were taken periodically (at least every thousand cycles, often more frequently) throughout the tests to monitor crack advance. Replication was done at room temperature and, as such, required the furnace to be shut off and the sample cooled to ambient.

An array of analytical tools was used to examine the role of microstructure on the initiation and propagation of small fatigue cracks. These tools included: 1) a scanning electron microscope (SEM) for fractography and orientation imaging microscopy (OIM) of material at and adjacent to the initiation sites, 2) a focused ion beam (FIB)-equipped SEM to reveal the microstructure in the areas of interest, 3) a software package that enabled quantitative fractographic measurements of the initiation sites and surrounding material (MeX by Alicona Imaging $\mathrm{GmbH}$ ) [9] and 4) a charge-coupled device (CCD) camera attached to an optical microscope for digital image correlation (DIC).

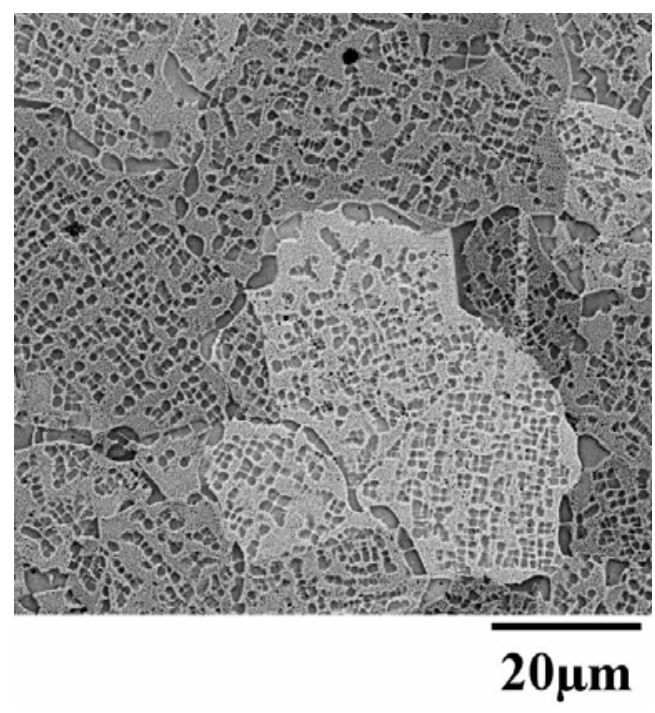

c)

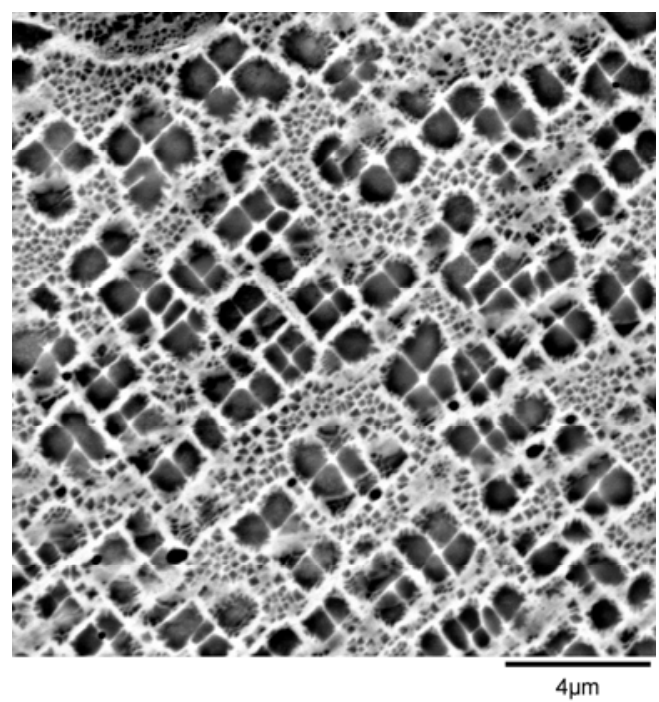

d)

Figure 1. Backscattered SEM images of a, b) René88DT and c,d) IN100 microstructures 


\section{Results and Discussion}

\section{René88DT Fatigue}

Surface replicas were used to monitor the advance of short cracks in three René88DT specimens. The initiation site for each of these was found to be non-metallic inclusions (NMI) located at the specimen surface. The lengths of each NMI exposed at the specimen surface are shown in Table 2. The NMI were similar in size, shape and composition. Fracture surfaces for each specimen are shown in Figure 2. The distinct thumbnail appearance and banding around each initiation site seems to be an artifact of the replication process which required periodic cool down to room temperature. The bands can highlight the amount of crack advance during a given cycle block. However, as shown in Figure 3, for the specimen identified as 'slow', there were blocks that showed signs of crack arrest or negligible growth (e.g. from 2000 to 6000 cycles).

Table 2: Information for cracks in René88DT selected for characterization.

\begin{tabular}{|c|c|c|c|}
\hline Crack ID & $\begin{array}{c}\text { Initiation } \\
\text { Type }\end{array}$ & $\begin{array}{c}\text { Surface length } \\
\text { of initiating } \\
\text { feature }(\mu \mathrm{m})\end{array}$ & $\begin{array}{c}\text { Cycles to } \\
120 \mu \mathrm{m}\end{array}$ \\
\hline Slow & NMI & 35 & $\sim 7700$ \\
\hline Medium & NMI & 45 & $\sim 4500$ \\
\hline Fast & NMI & 40 & $\sim 2100$ \\
\hline
\end{tabular}

In an effort to correlate fracture surface roughness at crack lengths (2a) less than $200 \mu \mathrm{m}$ to crack growth rate, stereopairs of each fracture surface were collected for input to the MeX software. A three-dimensional representation (digital elevation map) of each surface was created and area-based surface roughness measurements were made. A summary of the surface roughness measurements are shown in Table 3 . Using a lineintercept technique, the projected area is the planar measurement of the area of interest (i.e. length $\mathrm{x}$ width). An example of a grid placed over the initiation area of the 'slow' specimen is shown in Figure 4. The true area is a summation measurement of the changes in topography along the lines of the grid and root mean square (RMS) height is a value calculated by taking the square of the difference in height from a mean height. The qualitative statement, "all else being equal (i.e. material, testing conditions, etc.), the more tortuous a fracture surface, the longer the life" is supported by the quantitative findings reported in Table 3. The trends shown in Table 3, the higher the true/ projected ratio and the higher the RMS value, the slower the crack will advance hold true.

Table 3. Summary of surface roughness measurements near the initiation sites for René88DT specimens.

\begin{tabular}{|c|c|c|c|c|}
\hline & $\begin{array}{c}\text { projected } \\
\text { area }\left(\mu \mathrm{m}^{2}\right)\end{array}$ & $\begin{array}{c}\text { true area } \\
\left(\mu \mathrm{m}^{2}\right)\end{array}$ & $\begin{array}{c}\text { Ratio of } \\
\text { true/ } \\
\text { projected }\end{array}$ & $\begin{array}{c}\text { RMS } \\
\text { height } \\
(\mu \mathrm{m})\end{array}$ \\
\hline Slow & 19200 & 22557 & 1.175 & 3.109 \\
\hline Medium & 18186 & 20697 & 1.138 & 2.271 \\
\hline Fast & 19248 & 21433 & 1.114 & 2.093 \\
\hline
\end{tabular}

As mentioned earlier, variable growth rates exhibited by small fatigue cracks are often attributed to neighboring grain

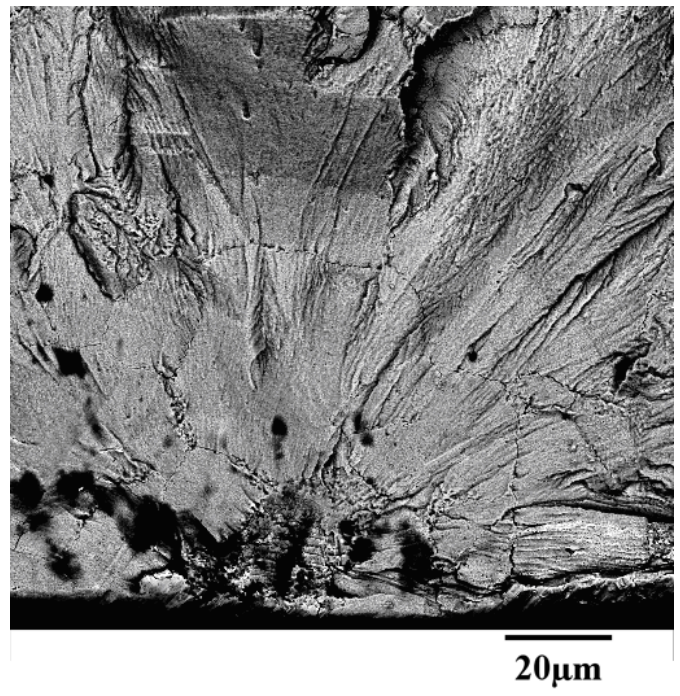

a)

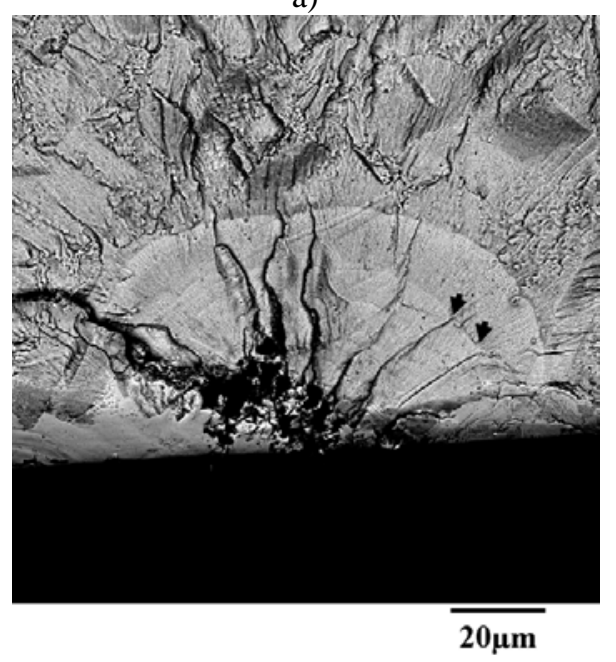

b)

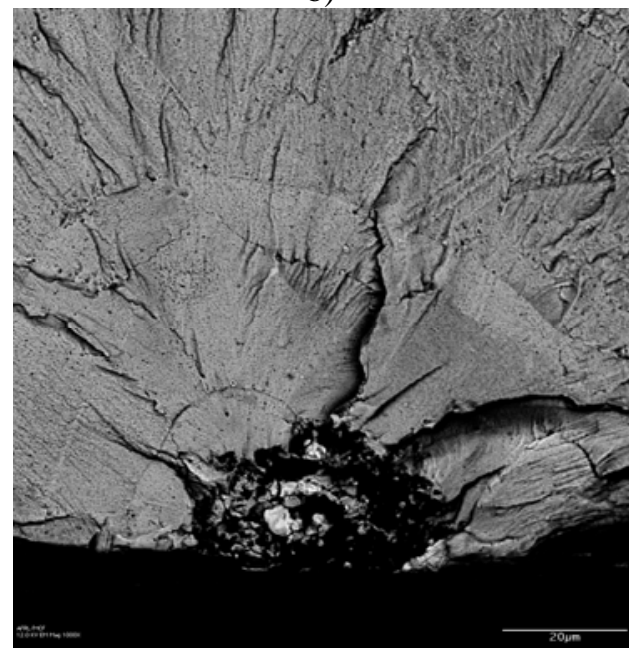

c)

Figure 2. Fracture surfaces and initiation sites from René88DT 
specimens. a) slow, b) medium, c) fast. Note arrows on b) indicating grain boundary.

misorientations. A good example of this is shown in Figure $2 b$. The arrows on Figure $2 b$ indicate the point at which two river lines terminate, indicating the presence of a grain boundary between two grains with appreciable misorientation. Crack advance is significantly slowed at this point in turn hindering movement of the entire crack front. The crack growth rate slows in this region as shown in Figure 3 for the 'medium' specimen from approximately 90 to $100 \mu \mathrm{m}$ (crack length, 2a, at the surface). This finding is in agreement with location of the arrows in Figure 3b which are found to be approximately $45 \mu \mathrm{m}$ (crack length, a, for subsurface) from the initiation site.

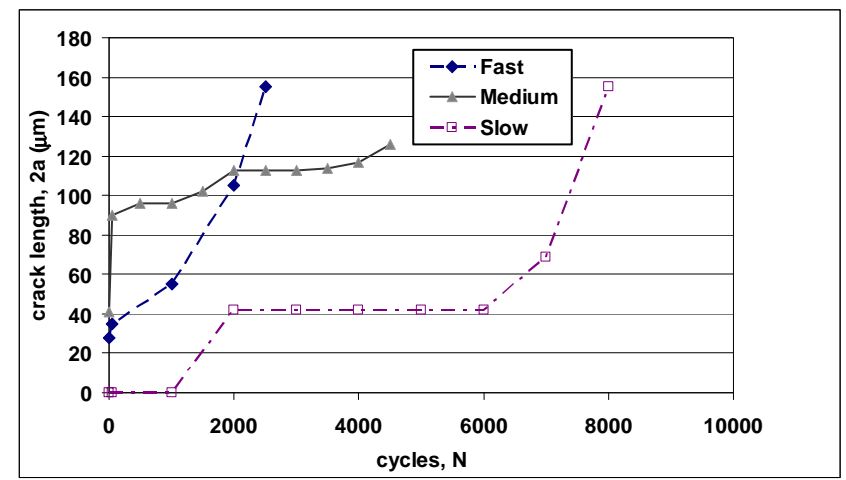

Figure 3. Surface crack size vs N for René88DT.

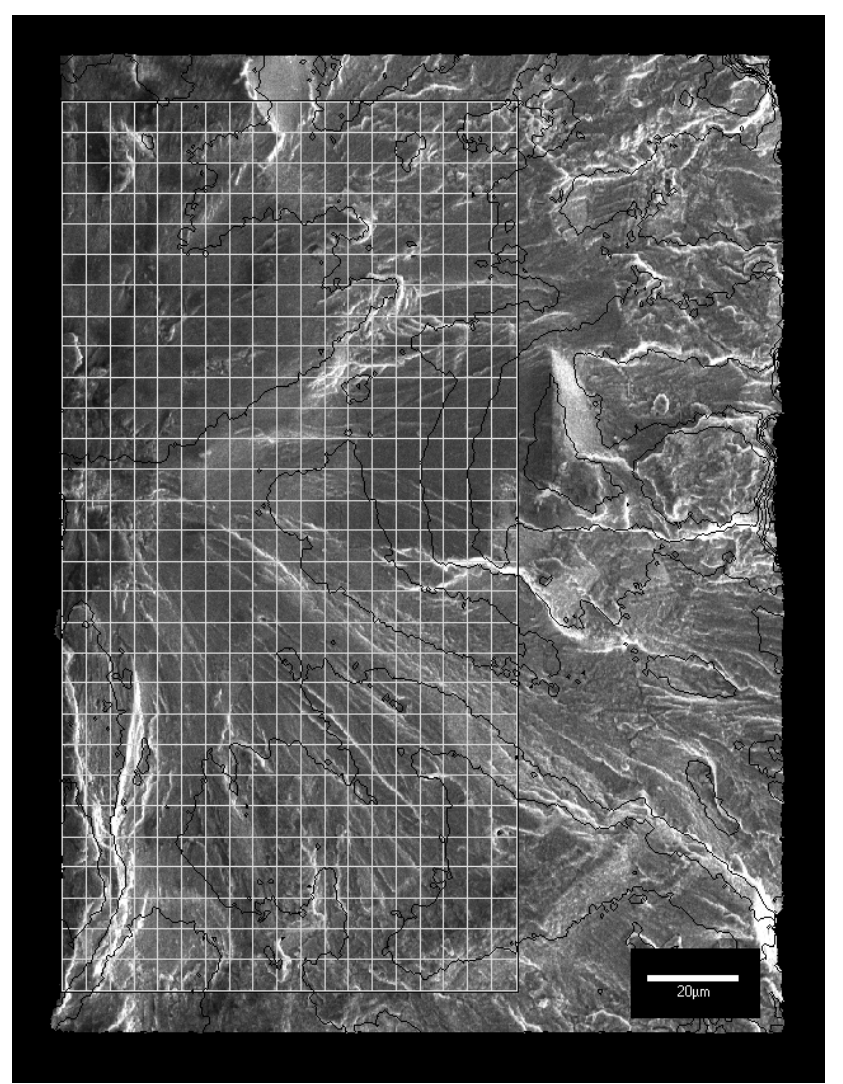

Figure 4. Grid used for line-intercept measurement of fracture surface roughness in René88DT ‘slow’ specimen.

\section{IN100 Fatigue}

Twenty one (21) IN100 specimens were tested in this portion of the study with fatal cracks initiating at either sites of porosity $(70 \%)$ or non-metallic inclusions (30\%). Most of the fatal cracks initiated at the surface of the specimen (60\%). due to the large number of pores as compared to NMI, the vast majority of the surface initiated cracks were associated with porosity. From this group, two specimens that initiated at pores on the specimen surface were selected for characterization. While the pore morphology and location within each specimen were very similar, a roughly $4 \mathrm{X}$ difference in cycles to failure (5105 vs 23,233 ) was exhibited. Information about the pores from each specimen is shown in Table 4. One point of interest is that the specimen initiating at the larger pore had longer life.

Table 4: Size and morphology of pores measured in IN100 specimens selected for characterization.

\begin{tabular}{|c|c|c|c|c|}
\hline $\begin{array}{c}\text { Specimen } \\
\text { ID }\end{array}$ & $\begin{array}{c}\text { Cycles to } \\
\text { failure }\end{array}$ & $\begin{array}{c}\text { Pore } \\
\text { Diameter } \\
(\mu \mathrm{m})\end{array}$ & $\begin{array}{c}\text { Pore } \\
\text { Area } \\
\left({\left.\mu \mathrm{m}^{2}\right)}^{2}\right.\end{array}$ & $\begin{array}{c}\text { Aspect } \\
\text { ratio }\end{array}$ \\
\hline long life & 23,233 & 32.5 & 831 & 1.1 \\
\hline short life & 5,105 & 20.3 & 326 & 1.0 \\
\hline
\end{tabular}

The next step was to use the FIB to prepare the material beneath and surrounding the initiation sites for OIM imaging. Figure 5b and e show post-FIB, backscattered electron images of each of the IN100 specimens revealing the supersolvus microstructure. Figure $5 \mathrm{c}$ and $\mathrm{f}$ show the electron backscattered diffraction (EBSD) images for each specimen.

As expected, given the P/M processing route used for the IN100, the OIM information from each specimen reveals a microstructure with no strong overall texture. The most noteworthy difference in the OIM data between the two specimens is the presence of more twin boundaries in the long life specimen. Efforts are continuing to determine whether this difference in the amount of twinning in the short crack region is a factor contributing to variable fatigue behavior. Other factors under investigation include quantitative analysis using the OIM data of the types of grain boundaries present in the areas of interest. A preponderance of high angle (large misorientation) versus low angle (small misorientation) grain boundaries has been shown to substantially hinder crack growth rates and may play a significant role in fatigue variability.

\section{$\underline{\text { René88DT Tensile/ Image Correlation }}$}

In addition to the fatigue variability study with microstructure, tensile testing was performed while imaging the deformation behavior of the local microstructure. Electron Backscatter Diffraction (EBSD) was first performed in an area of interest on the surface of a René88DT specimen in order to obtain the local 


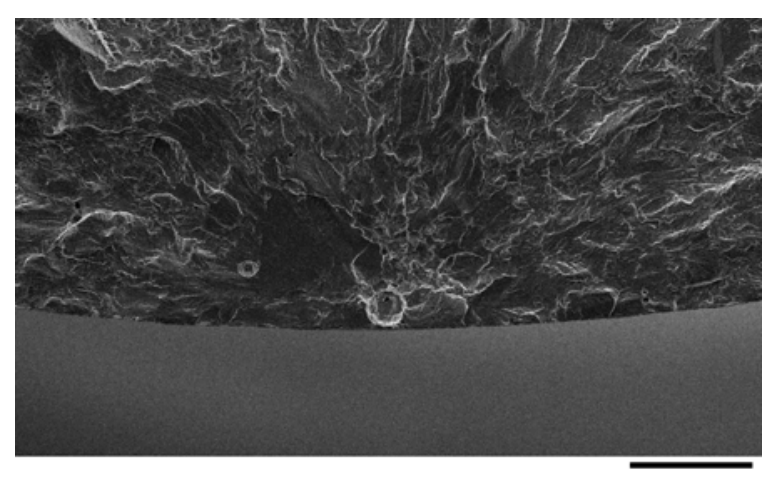

$100 \mu \mathrm{m}$

a)

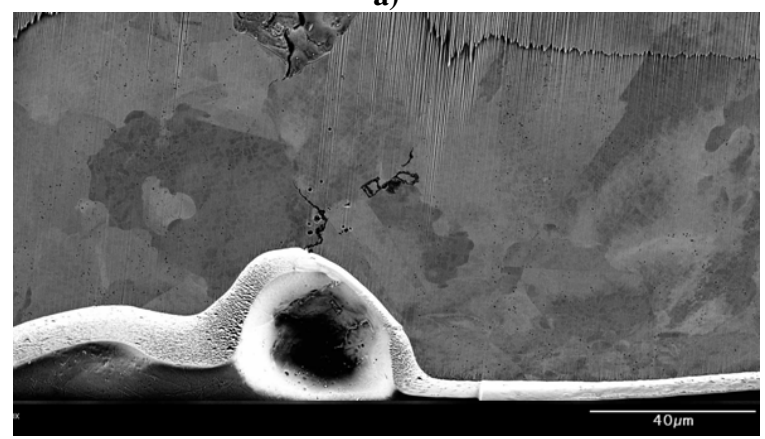

b)

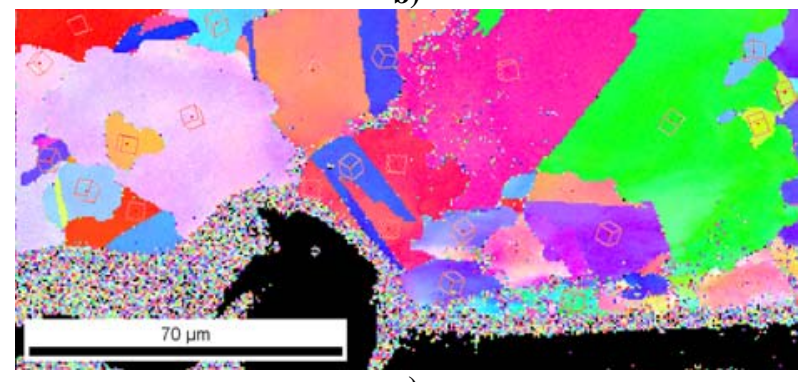

c)

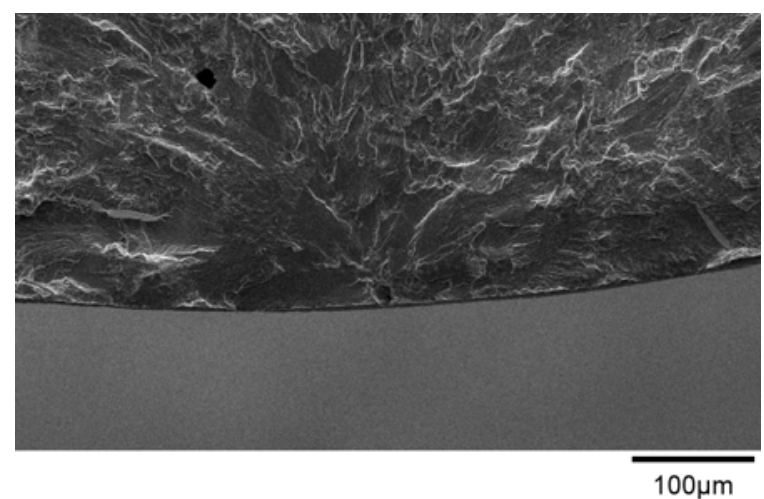

d)

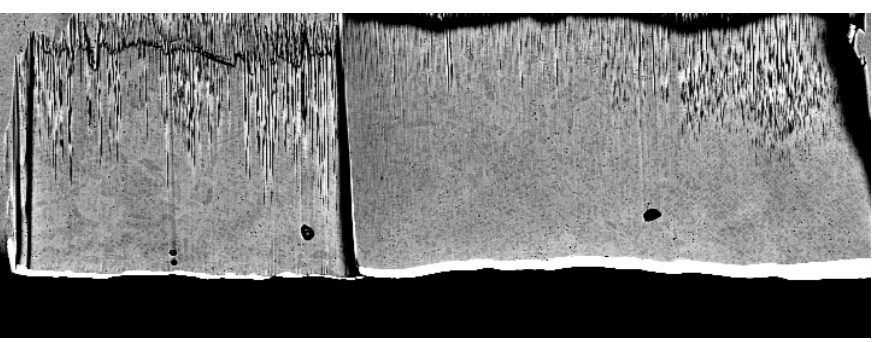

e)

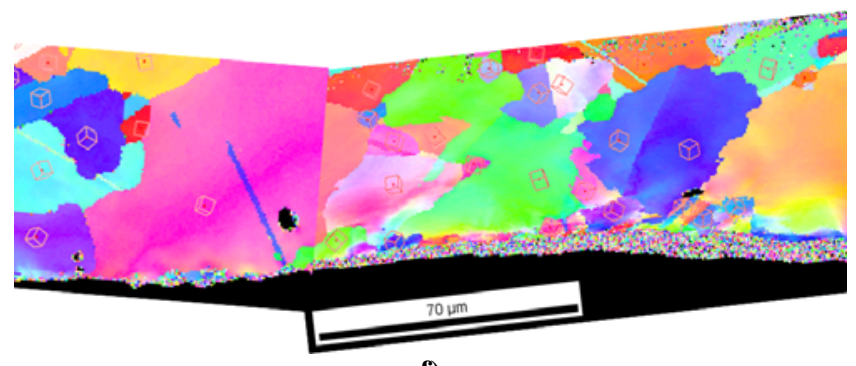

f)

Figure 5. SEM images of the IN100 fracture surfaces before FIB milling, (a, d), after FIB milling, (b, e), and OIM images from the FIB-milled surfaces, (c, f). Figs. a,b,\&c) correspond to the long-life specimen; Figs. d,e,\& f to the short-life specimen.

orientation (Figure 6). The orientation values were used to obtain the grain boundary misorientation (Figure 7). During the tensile test, images were taken of the area of interest with a CCD camera and an optical microscope. The strain distribution calculated using Vic-2D digital image correlation software (Figure 8) [10, 11]. The EBSD data was combined with the optical data to compare the effect of orientation on the plastic strains. The highest strain concentrations are located near the boundary of the large grain shown in the image. While several twins within the large grain show elevated strain levels, most of the high strain areas occur near high misorientation angle grain boundaries.

The grain boundary misorientation directly affects the micromechanical behavior in the above microstructure. Strain concentrations near twice the mean strain or higher are observed near high angle misorientation grain boundaries. Other factors such as neighboring grain shapes and sizes and orientation with respect to the loading direction also contribute to the observed elevated strain levels.

Due to experimental limitations, the data presented is on the surface only two dimensional, even though the problem is three dimensional. Therefore, the subsurface grain properties and the out of plane displacements are unknown. While the ability to measure these three dimensional properties would increase the accuracy and the confidence in the experimental results, the trends due to grain boundary misorientation and twinning would stay the same. The twinning also produced some strain concentrations of significance when compared to grain boundary misorientations. Further investigation at higher magnifications is necessary to compare and contrast the local strain behavior of grain boundaries and twin boundaries and their importance in crack initiation and propagation behavior relating to fatigue variability. 


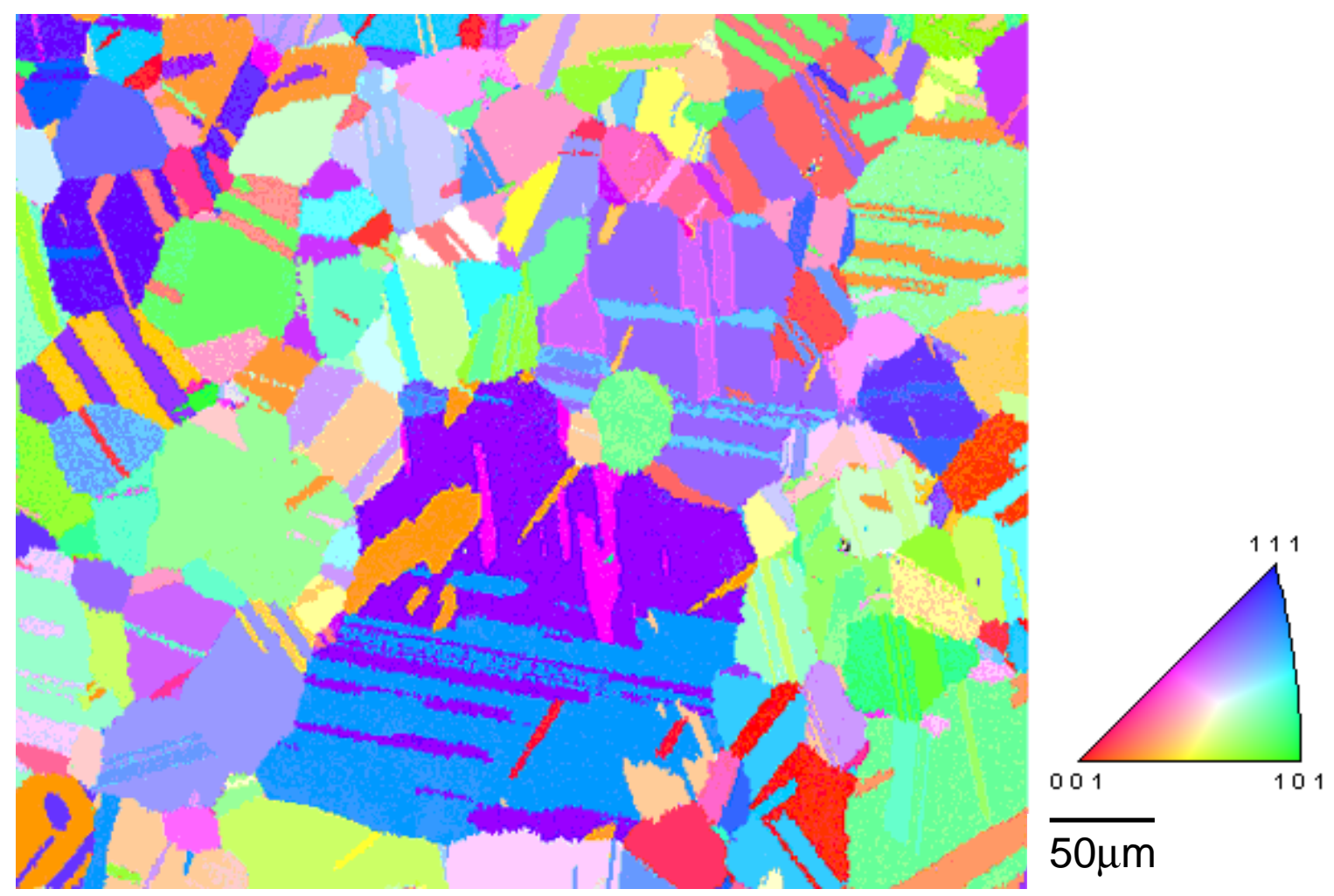

Figure 6: Inverse pole figure of area imaged during deformation mapping.

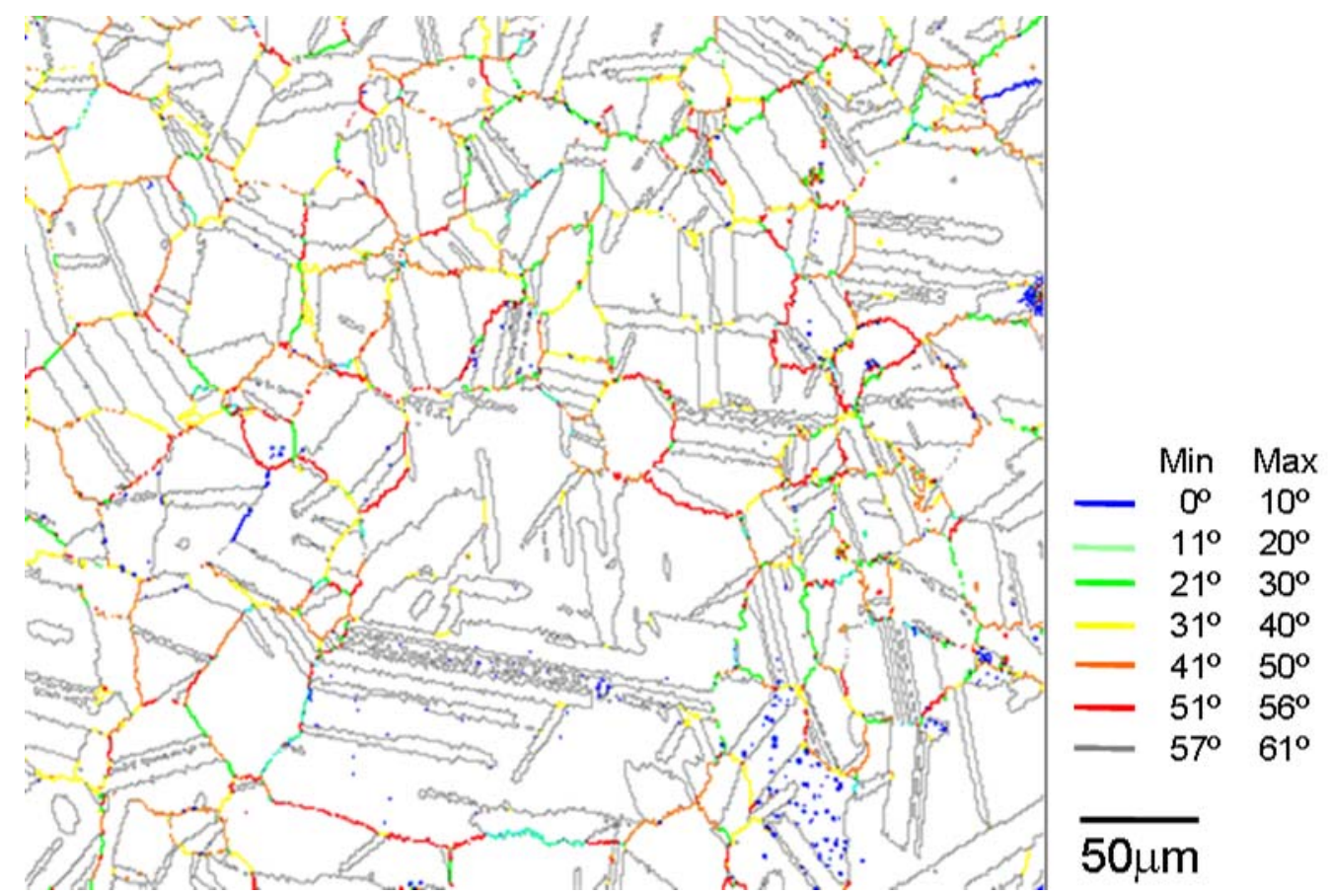

Figure 7: Grain boundary misorientation map near large center grain. 


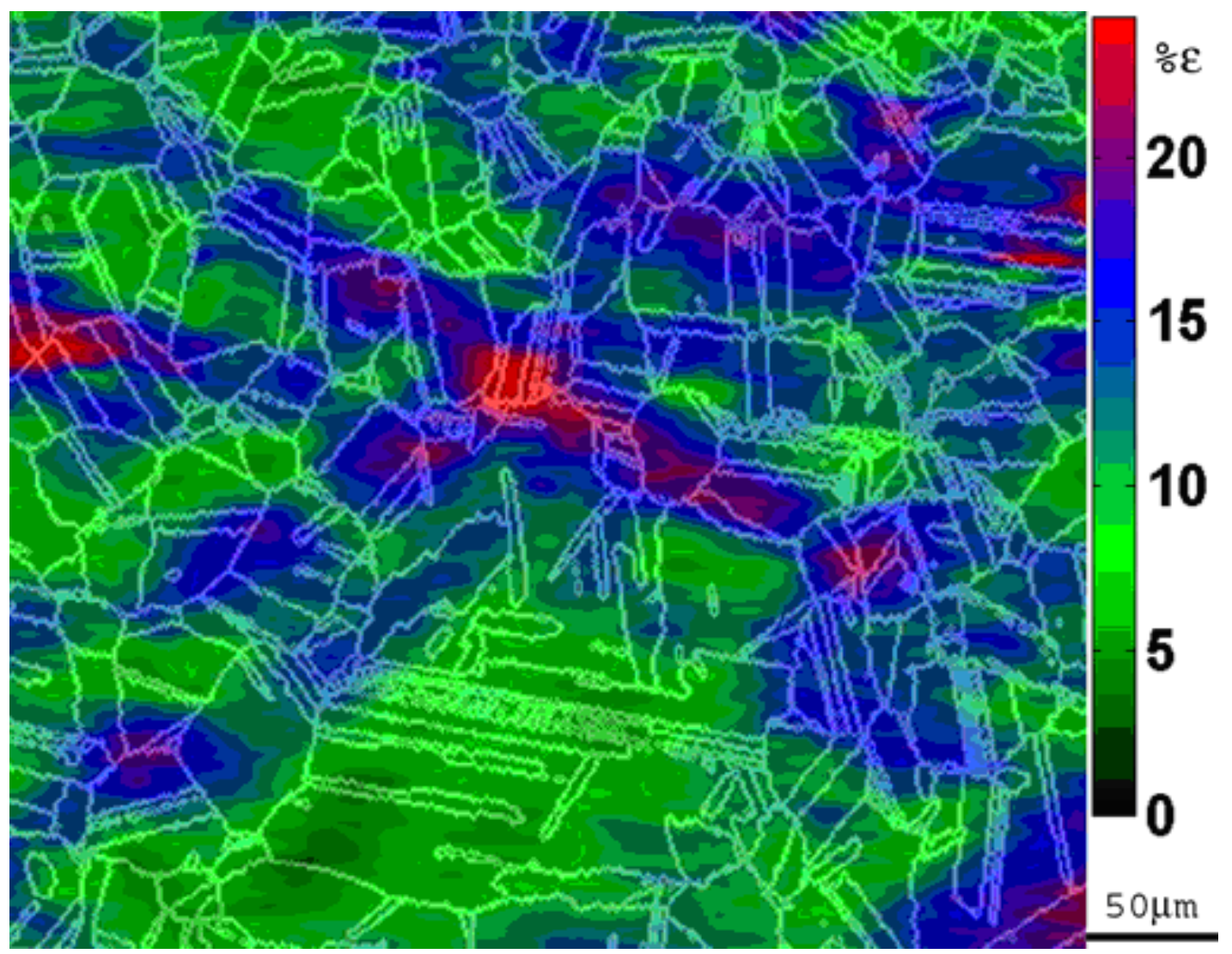

Figure 8: Total strain field of area of interest with a mean total strain at $10 \%$ at $1400 \mathrm{MPa}$ tensile stress.

\section{Conclusions}

René88DT and IN100 LCF specimens that exhibited dissimilar small fatigue crack growth rates and variable cycles to failure, respectively, were examined to determine the microstructural conditions responsible for each behavior. A digital image correlation technique was employed on a René88DT tensile specimen to determine how and where plastic strains develop during loading.

\section{References}

1. J. Luo and P. Bowen, "Small and Long Fatigue Crack Growth Behaviour of a PM Ni-Based Superalloy, Udimet 720,” Int. J. Fatigue, Vol. 26, pp. 113-124, 2004.

2. M. Goto and D.M. Knowles, "Initiation and Propagate Behaviour of Microcrakcs in Ni-Base Superalloy Udimet 720 LI," Engineering Fracture Mechanics, Vol. 60, No. 1, pp. 1-18, 1998.

3. M. J. Caton, S. K. Jha, A. H. Rosenberger, and J. M. Larsen, "Divergence of Mechanisms and the Effect on the Fatigue Life Variability of René88DT,” Superalloys 2004, Edited by K.A. Green, T.M. Pollock, H. Harada, T.E. Howson, R.C. Reed, J.J. Schirra, and S, Walston, TMS (The Minerals, Metals \& Materials Society), pp. 305-312, 2004.
4. A. Boyd-Lee and J.E. King, "Short Fatigue Crack Path Determinants in Polycrystalline Ni-Base Superalloys," Fatigue Fract. Engrg. Mater. Struct., Vol. 17, No. 1, pp. 1-14, 1994.

5. M. Marchionni, G.A. Osinkolu, and G. Onofrio, "High Temperature Low Cycle Fatigue Behaviour of Udimet 720 LI Superalloy,” Int. J. Fatigue, Vol. 24, pp. 1261-1267, 2002.

6. E.S. Huron and P. G. Roth, "The Influence of Inclusions on Low Cycle Fatigue Life in a P/M Nickel-Base Disk Superalloy," Suoerallovs 1996, Edited by R. D. Kissinger, D. J. Deye, D. L. Anton, A. D. Cetel, M. V. Nathal, T. M. Pollock, and D. A. Woodford, The Minerals, Metals \&Materials Society, pp 359-368, 1996.

7. A.D.Boyd-Lee, "Fatigue Crack Growth Resistant Microstrucutres in Polycrystalline Ni-Base Superalloys for Aeroengines,” Int. J. Fatigue, Vol. 21, pp. 393-405.

8. D.D. Krueger, R.D. Kissinger, and R.G. Menzies, Development and Introduction of a Damage Tolerant High Temperature NickelBase Superalloy, René88DT,” Superallovs 1992, Edited by S.D. Antolovich, R:W. Stusrud, R.A. MacKay, D.L. Anton, T. Khan, R.D. Kissinger, D.L. Klarstrom, The Minerals, Metals \& Materials Society, 1992, pp. 277-286. 
9. A. Shyam and W.W. Milligan, "Effects of Deformation Behavior on Fatigue Fracture Surface Morphology in a Nickelbase Superalloy,” Acta Materialia, Vol 52, pp. 1503-1513, 2004.

10. Vogel, D., Gollhardt, A., Michel, B., "Micro and Nanomaterials Characterization by Image Correlation Methods," Sensors and Actuators A, Vol. 99, pp. 165-171, 2002.

11. Wang, Q., Chiang, F. P., "Experimental Characterization of Interphase Mechanical Properties of Composites," Composites Part B: Engineering, Vol. 27, pp. 123-128, 1996. 